\title{
Genotype-Phenotype correlations in Joubert Syndrome in the Era of Next Generation Sequencing
}

\author{
R Bachmann-Gagescu*, J Dempsey², IG Phelps², C Isabella², D O'Day², B O'Roak ${ }^{3}$, J Shendure ${ }^{3}$, I Glass², \\ D Doherty ${ }^{2}$
}

From Cilia 2014 - Second International Conference

Paris, France. 18-21 November 2014

\section{Objective}

To provide extensive genotype-phenotype correlations for Joubert syndrome (JS), a ciliopathy characterized by a distinctive hindbrain malformation ("the molar tooth sign"), ataxia and cognitive dysfunction.

\section{Methods}

Phenotypic data was collected from the University of Washington JS cohort and all known JS genes were sequenced in 429 individuals (364 families) using the MIPS capture technique and next-generation sequencing.

\section{Results}

Core JS diagnostic features (hypotonia, ataxia, cognitive dysfunction, oculo-motor apraxia) were present in $>80 \%$ of individuals, while abnormal breathing pattern was reported in $60 \%$. Frequently associated features included retinal dystrophy (31.4\%), renal disease (20.9\%), coloboma $(17.7 \%)$, polydactyly (15.3\%), liver fibrosis $(15.2 \%)$ and encephalocele (8\%). Liver fibrosis and coloboma were strongly associated with each other (Odds Ratio 7.0, 95\% Confidence Interval $=3.0-13.2$ ), while retinal dystrophy and renal disease were weakly associated (O.R. 2.2, 95\%C. $\mathrm{I} .=1.7-5.6)$. Additional clinical features included other brain abnormalities $(n=73)$, seizures $(n=49)$, cleft palate $(\mathrm{n}=16)$, hearing loss $(\mathrm{n}=14)$ and psychiatric problems $(n=45)$. The genetic cause was identified in $60 \%$ of families, with 5 genes accounting for the majority of patients (C5ORF42, CEP290, CC2D2A, AHI1, TMEM67). Bi-allelic causal mutations in $B 9 D 2$ and $C 2 C D 3$ were identified in 2 families each. Bi-allelic mutations in 2 different genes were identified in 4 families and heterozygous mutations (in addition to the causal mutation) were present in 62 individuals. Significant $(\mathrm{p}<0.0001)$ genotype-phenotype correlations were observed: $C E P 290$ with renal disease and retinal dystrophy; TMEM67 with liver fibrosis and coloboma.

\section{Conclusion}

This study provides a comprehensive description of the phenotypic spectrum, genetic makeup and genotypephenotype correlations of a large JS cohort.

\section{Authors' details}

${ }^{1}$ Institute for Molecular Life Sciences and Institute for Medical Genetics, University of Zurich, Zurich, Switzerland. ${ }^{2}$ Pediatrics, University of Washington, Seattle, WA, USA. ${ }^{3}$ Genome Sciences, University of Washington, Seattle, WA, USA.

Published: 13 July 2015

\section{doi:10.1186/2046-2530-4-S1-P8}

Cite this article as: Bachmann-Gagescu et al:: Genotype-Phenotype correlations in Joubert Syndrome in the Era of Next Generation Sequencing. Cilia 2015 4(Suppl 1):P8. 